\title{
Fabrication of Polymer/ZnS nanoparticle composites by matrix-mediated synthesis
}

Tomonari Ogata $^{1,2^{*}}$, Norio Hirakawa ${ }^{3}$, Yuuki Nakashima ${ }^{3}$, Yutaka Kuwahara ${ }^{2,3}$, and Seiji Kurihara ${ }^{2,3,4 \dagger}$

${ }^{1}$ Innovative Collaboration Organization, Kumamoto University, 2-39-1 Kurokami,

Kumamoto 860-8555, Japan.

${ }^{2}$ Kumamoto Institute for Photo-Electro Organics (PHOENICS), 3-11-38 Higashimachi,

Kumamoto, 862-0901, Japan

${ }^{3}$ Graduate School of Science and Technology, Kumamoto University, 2-39-1 Kurokami, Kumamoto 860-8555, Japan.

${ }^{4}$ JST, CREST, 7 Gobancho, Chiyoda-ku, Tokyo 102-0076, Japan.

*Corresponding author. Tel. +81963423967 Fax +81963423239

E-mail address: t_ogata@kumamoto-u.ac.jp (T. Ogata)

†Corresponding author. Tel. +81963423676 Fax +81963423679

E-mail address: kurihara@kumamoto-u.ac.jp (S. Kurihara) 


\begin{abstract}
Zinc sulfide nanoparticles are obtained as primary particles in a polymer matrix by a matrix-mediated synthesis. Two types of matrix polymer are synthesized via the copolymerization of hydrophobic, cation-exchange, and cross-linking monomers. The $\mathrm{ZnS}$ nanoparticles are affected by the composition of the matrix polymer, and especially by its hydrophobicity. In a low-hydrophobicity copolymer matrix, aggregates of ZnS nanoparticles are observed in the matrix using transmission electron microscopy (TEM) and X-ray diffraction (XRD). In a high-hydrophobicity cation-exchange copolymer matrix, primary particles of $\mathrm{ZnS}$ with $2-5 \mathrm{~nm}$ diameters are observed in the matrix by TEM. However, the $\mathrm{ZnS}$ pattern is not distinguishable in XRD measurements because the particle sizes are too small to diffract X-rays.
\end{abstract}

\title{
Keywords
}

Nanoparticle, Dispersion, Polymer composite, Refractive index, Zinc sulfide

\section{Introduction}

Recently, inorganic nanoparticles have attracted much interest as they can form 
quantum dots and are used in photocell [1-3], lasing [4-7], and fluorescent devices [8-11]. Methods for producing quantum dots include electron beam lithography [12-14], molecular beam epitaxy [15-17], and liquid phase synthesis [18-20]. The bulk production of quantum dots using liquid phase synthesis creates aggregates due to the high surface energy of the particles [21,22]. This aggregation changes the dots' character and fluorescence wavelength, and it is therefore important that particles remain dispersed and independent in their medium. Embedding quantum dots in polymers can prevent dot aggregation, and quantum dots/polymer composites have practical applications; however, successfully mixing the quantum dots into the polymer is difficult.

Another application of nanoparticle materials is use as a refractive index modifier of polymers. High refractive index polymers are used in optical applications such as optical communication, organic electroluminescence and light-emitting diodes (LEDs) and, in the future, in optical computers. High refractive index polymers are flexible, light-weight, and easy to micro-fabricate using soft processes. However, the refractive index of organic materials is low relative to inorganic compounds because the main component atom is carbon, which has low atomic refractivity. Many studies have 
reported on the improvement of the refractive index of polymer materials, and one of the most effective methods is by compositing the polymer with inorganic nanoparticles [23-28]. Zinc sulfide is well known for its high refractive index $[21,24,29,30]$ and fluorescence properties [31,32,33]. Although this compositing appears to be simple, there are some intractable problems that occur when using nanoparticles. Particularly, the aggregation of particles during the mixing of the nanoparticles and the polymer is major problem. Once nanoparticle aggregates are generated, breaking them down and redispersing the nanoparticles is very difficult. Surface modification of the polymers and the use of surfactants are effective ways to prevent aggregation [34-38], however the advantageous effects of nanoparticles are reduced by these additional components.

To solve these problems, the production of nanoparticles in the polymer in situ is effective because the particles are confined in the polymer chain network. Ziolo et al. reported the matrix-mediated synthesis of composites consisting of nanoparticles and polymers using an ion-exchange polymer as the matrix [39]. The $\gamma-\mathrm{Fe}_{2} \mathrm{O}_{3}$ particles in the polymer matrix were primary particles and the composite was optically transparent and superparamagnetic. This method, therefore, is useful for producing nanoparticles of metal compounds without aggregation. In this study, we modify Ziolo's method to 
fabricate zinc sulfide/polymer composites.

\section{Experimental}

\subsection{Materials}

Methylmethacrylate (MMA, Tokyo Chemical Industry Co., Ltd. Tokyo, Japan) was washed with $5 \mathrm{wt} \%$ sodium hydroxide solution and distilled $\left(110 \mathrm{mmHg}, 40^{\circ} \mathrm{C}\right)$ before use. 2-Acrylamido-2-methyl-1-propanesulfonic acid (AMPS, Tokyo Chemical Industry Co., Ltd. Tokyo, Japan) was recrystallized from ethanol before use. Trimethylolpropanetriacrylate (TMPTA), sodium styrene sulfonate (NaSS) and trichloro(3,3,3-trifluoropropyl)silane were purchased from Sigma-Aldrich Japan (Tokyo, Japan) and used without further purification. Styrene (St, Wako Pure Chemical Industries, Ltd. Osaka, Japan) was treated with a silica column and distilled (110 mmHg, $40^{\circ} \mathrm{C}$ ) before use. Divinylbenzene (DVB, Nacalai Tesque, Inc. Kyoto, Japan) was treated with a silica column to remove the inhibitor before use, and $\alpha, \alpha^{\prime}$-azobisisobutyronitoryl (AIBN, Nacalai Tesque, Inc.) was recrystallized from ethanol before use. Sodium hydrosulfide (Nacalai Tesque, Inc.) was used without further purification. Zinc chloride and hydrogen peroxide were purchased from Wako 
Pure Chemical Industries, Ltd. (Osaka, Japan) and used without purification. Methanol and dimethyl sulfoxide (DMSO, Nacalai Tesque, Inc. Kyoto, Japan) were dried with molecular sieves before use.

\subsection{Synthesis}

\subsubsection{Polymerization of matrix polymer}

Glass plates $(76 \times 72 \times 1 \mathrm{~mm})$ were immersed in a $1 \mathrm{wt} \%$ of trichloro(3,3,3-trifluoropropyl)silane aqueous solution for $2 \mathrm{~h}$, washed well with water and dried. The glass reaction cell $(50 \times 40 \times 5 \mathrm{~mm})$ is assembled by coupling the silane-treated glass plates with a silicone rubber spacer $(5 \mathrm{~mm})$.

Two types of copolymers were synthesized, one of which was an MMA, AMPS and TMPTA copolymer and the other was an St, NaSS and DVB copolymer. The monomers were mixed using the ratios given in Tables 1 and 2. A mixture using the monomers and $20 \mathrm{mg}$ of AIBN were dissolved in various amounts of DMSO, as tabulated in Tables 1 and 2, and placed in the glass reaction cell and heated to polymerization for $15 \mathrm{~h}$ in an air oven $\left(50^{\circ} \mathrm{C}\right)$. After polymerization, the resulting polymer plate was taken from the reaction cell and immersed in water to extract any unreacted monomer and DMSO. The water was changed three times in a 72-h period. For the St-NaSS-DVB copolymer, the 
polymer plates were immersed in $1 \mathrm{~N} \mathrm{HCl}$ for $24 \mathrm{~h}$ to protonate the sodium sulfonate moiety in the NaSS, and subsequently washed with water several times. Next, the plates holding the MMA-AMPS-TMPTA and St-NaSS-DVB copolymers were immersed in methanol and the methanol was changed four times in a 12-h period. After this purification, the polymer plates were dried in vacuo at room temperature.

\subsubsection{Generation of metal compound nanoparticles}

The polymer matrixes were immersed in $0.1 \mathrm{~mol} \cdot \mathrm{dm}^{-3}$ of zinc chloride aqueous solution for $12 \mathrm{~h}$, during which the zinc cation content in the solution was adjusted to match the cation-exchange capacity of the polymer matrix. The polymer matrix containing the zinc ions was immersed in water to remove free zinc ions, and subsequently in methanol to remove the water and dry the matrix. After drying, the polymer plates containing the zinc ions were immersed in $1.0 \mathrm{~mol} \cdot \mathrm{dm}^{-3}$ of sodium hydrosulfide aqueous solution for $12 \mathrm{~h}$ for sulfurization. The polymer was then removed from the solution and washed with water several times. After drying, the polymer plates containing zinc sulfide were obtained.

\subsection{Characterization}


Transmission electron microscope (TEM, JEM-2000FX; JEOL Ltd. Tokyo, Japan) analyses were performed at an accelerating voltage of $200 \mathrm{kV}$ for thin sample sections of $50 \mathrm{~nm}$ thickness prepared by microtomy using an ultramicrotome (EM-UC7; Leica Microsystems K.K. Tokyo, Japan) equipped with a diamond knife. The metal content in the composite was estimated by thermogravimetric analysis (TGA, TG/DTA6300S SII NanoTechnology Inc. Tokyo, Japan) under air atmosphere. The polymer sample was prepared for TGA by placing it in platinum pan and heating it from room temperature to $800{ }^{\circ} \mathrm{C}$ at a rate of $10{ }^{\circ} \mathrm{C} / \mathrm{min}$. The metal content of the residue was estimated to be zinc oxide from the weight of the residue. Fourier transform infrared (FT-IR) spectroscopy (Spectrum One PerkinElmer Japan Co., Ltd., Japan) was performed using the attenuated total reflection (ATR) attachment in the range from $4000-500 \mathrm{~cm}^{-1}$ to confirm the functional groups in the polymers. The X-ray diffraction (XRD) patterns (RINT2500HV Rigaku Co. Tokyo, Japan) were collected with an instrument equipped with a $\mathrm{Cu}$ target X-ray source. The refractive indices of the composites were measured with an Abbe refractometer (NAR-1T, ATAGO Co., Ltd. Tokyo, Japan) equipped with a monochromated (589 nm) filament lamp using 1-bromonaphthalene as a mediator.

\section{Results and discussion}




\subsection{Modification of Ziolo's method}

We modified Ziolo's method to generate zinc sulfide (Fig. 1): Zinc ions are absorbed into a polymer that has an ion-exchangeable group. Next, the zinc ions are converted to zinc sulfide using sodium hydrosulfide. We explored suitable compositions of the base polymer to produce a transparent zinc sulfide/polymer composite.

\section{Figure 1}

\subsection{Synthesis of the MMA-AMPS-TMPTA matrix polymer}

We found that the hydrophilicity, cross-linking density and ion-exchange group of the matrix polymer are the main factors governing the production of nanoparticles and the resulting composites. MMA-AMPS-TMPTA copolymers with various composition ratios are polymerized between two glass plates which have been treated with trichloro(3,3,3-trifluoropropyl)silane to prevent the polymer from sticking on the glass surface. After washing, the resulting polymer plates are dried and transparent and flat polymer plates are produced. The different compositions ratios of the polymers are given in Table 1. The MMA:AMPS ratio was varied under the same TMPTA content at Sample \#1 \#5, and TMPTA content was varied under the same MMA:AMPS ratio at 
Sample \#6 \#9. An FT-IR analysis is carried out to confirm the structure of a typical MMA-AMPS-TMPTA copolymer (Sample \#6), and the resulting spectrum is shown in Figure 2(a). The IR spectrum of the copolymer has characteristic bands from the AMPS at $3700-3200 \mathrm{~cm}^{-1}$, which are indicative of $-\mathrm{NH}$ and $-\mathrm{OH}$ stretching vibrations; at 1645 $\mathrm{cm}^{-1}$, which is indicative of Amide I; and at $1545 \mathrm{~cm}^{-1}$, which is indicative of AmideII [40,41]. The bands indicating the presence of sulfonic acid groups at 1230, 1030 [41] and. $1150 \mathrm{~cm}^{-1}$ are due to the $-\mathrm{OCH}_{2}$ stretching band of TMPTA [42]. The band at 1720 $\mathrm{cm}^{-1}$ is due to the $\mathrm{C}=\mathrm{O}$ stretching band in MMA and TMPTA $[42,43]$, and the bands at 1447 and $1225 \mathrm{~cm}^{-1}$ are due to the $-\mathrm{CH}_{3}$ bending and $-\mathrm{C}-\mathrm{O}-\mathrm{C}$ asymmetric stretching bands in MMA, respectively [43]. The broad around $3400 \mathrm{~cm}^{-1}$ is due to the $-\mathrm{OH}$ stretching band from water molecules involved in hydrogen bonding with sulfonic group[44]. The FTIR spectrum therefore confirms the presence of the three monomer units consisting of MMA, AMPS, and TMPTA in the copolymer structure.

\section{Table1}

Figure2

\subsection{Introducing zinc sulfide into the MMA-AMPS-TMPTA matrix polymer}


The MMA-AMPS-TMPTA copolymer plates are treated with a zinc chloride aqueous solution, upon which the appearance of the polymer plates becomes slightly cloudy. After washing and drying, the polymer plates absorbed zinc ions, are treated with a sodium hydrosulfide aqueous solution to convert the zinc ions into zinc sulfide. After sulfurization, the polymer plates are slightly yellow. To confirm the generation of zinc sulfide, XRD, TEM and TGA measurements are taken. In the XRD patterns of Sample \#6, the peaks match the reference zinc sulfide [40] diffraction patterns (Fig. 3). The TEM images show large structures 100-200 nm in size (Fig. 4(a)) which can be distinguished at higher resolution to be a cluster of many primary particles (Fig. 4(b)). The diameters of the individual particles in the cluster are observed to be approximately 2-5 nm. Figure 4 illustrates that the sizes of the nanoparticle clusters are $\sim 100 \mathrm{~nm}$ for all of the different wt\% of the TMPTA (Samples \#6, \#7, \#8).

\section{Figure3}

\section{Figure4}

Particle aggregation is likely to occur after the formation of zinc sulfide because each

primary particle in the aggregate exists individually. The nanoparticles are able to move 
through the polymer network because of the expansion of the network in the high-pH sodium hydrosulfide solution.

The amount of zinc sulfide in the clusters is determined by TGA wherein the zinc sulfide in the polymer composite is oxidized. Figure 5 shows the TG thermogram of the MMA-AMPS-TMPTA copolymer (Sample \#3) and of the composite polymer embedded $\mathrm{ZnS}$. The thermal degradation of the base polymer commences at $200{ }^{\circ} \mathrm{C}$ and is complete at $530{ }^{\circ} \mathrm{C}$. The composite polymer exhibits a similar behavior to that of the base polymer, and the TG curve reaches a constant value at temperatures over $530{ }^{\circ} \mathrm{C}$. The zinc content is calculated from the weight of the remaining zinc oxide residue, and the embedded zinc to AMPS equivalent ratio is calculated from the ratio of the equivalent of the embedded zinc for the cation-exchange site in the composite. The zinc to cation-exchange site mole ratio should be 1:2 at stoichiometric absorption, because two sulfonic acid groups are required to absorb one zinc ion. Figure 6 shows the embedded zinc to AMPS equivalent ratio as a function of the AMPS content in the copolymer.

\section{Figure 5}

\section{Figure 6}


The embedded equivalent amount of zinc is less than the AMPS content and increases as the AMPS content increases in the copolymer. As the polymer swells with increasing hydrophilicity this promotes the diffusion of zinc ions. Figure 7 shows the embedded zinc to AMPS equivalent ratio as a function of the copolymer with varying cross-linking content (TMPTA). Increasing the cross-linking ratio causes the zinc equivalent ratio to decrease.

\section{Figure7}

This result is similar to the effect of the AMPS content on the zinc content ratio, since the polymer network does not expand with increasing cross-linking ratios. The amount of absorption is affected not only by the AMPS content but also by the swelling ratio. The swelling also promotes undesired migration of nanoparticles to form clusters; the color changes observed in the sulfurized polymer composites are attributed to the diffracted light from zinc sulfide clusters.

\subsection{Synthesis of St-NaSS-DVB matrix polymers}

In the MMA-AMPS-TMPTA copolymers, suppression of the swelling to prevent the 
migration of nanoparticles while still keeping a high cation-exchange capacity was difficult. More hydrophobicity is required to suppress the swelling, so we chose St as the base polymer, DVB as the cross-linking polymer, and NaSS as the cation-exchange moiety to achieve the co-existence of reduced swelling and a high cation-exchange capacity. Using these monomers, various compositions of copolymers are synthesized (Table 2). The St:NaSS ratio was varied under the almost same DVB content at Sample $\# 10-\# 18$, and DVB content was varied under the same St:NaSS ratio at Sample \#19 \#26

\section{Table2}

The FT-IR analyses are carried out to confirm the structure of the typical St-NaSS-DVB copolymer and of the protonated St-NaSS-DVB copolymer (Sample \#19) in Figure 2(b) and 2(c), respectively. The bands at $3100-3000 \mathrm{~cm}^{-1}$ are due to $\mathrm{Ar}-\mathrm{H}$ stretching $[44,46]$, and those at 2920 and $2845 \mathrm{~cm}^{-1}$ are attributed to the $-\mathrm{CH}_{2}$ - asymmetric stretching band and the $-\mathrm{CH}_{2}$ - stretching band, respectively [46]. The band at $1180 \mathrm{~cm}^{-1}$ results from the presence of a sulfonate group in the St-NaSS-DVB copolymer structure [47], and is not observed in the protonated St-NaSS-DVB copolymer. The band at $1030 \mathrm{~cm}^{-1}$ and 1005 $\mathrm{cm}^{-1}$ is attributed to the $\mathrm{S}=\mathrm{O}$ stretching band [47] in both copolymers, and the bands at 680-760 and $1600 \mathrm{~cm}^{-1}$ are assigned to the $\mathrm{C}-\mathrm{C}$ vibrations of the benzene rings [46]. 
The FTIR spectrum therefore confirms the presence of a phenyl group and a sulfonic acid group in the copolymer, though it is difficult to distinguish the St, DVB, and NaSS. The peak attributed to the sulfonate group is seen to disappear after protonation of the copolymer, which indicates that the sodium sulfonate group is converted into sulfonic acid.

The shape of the resulting polymer plates is greatly affected by the composition of the monomers, and some compositions of the St-NaSS-DVB copolymer collapse into small pieces (Fig. 8).

\section{Figure 8}

This collapse is because the hydrophilicity based on the ionic group exceeds that of the cross-linking and hydrophobic groups. In some conditions, transparent and flat polymer plates are obtained. When the St:NaSS ratio is changed while keeping the cross-linking ratio around $10 \mathrm{~mol} \%$, the polymer plates with a St content under $60 \mathrm{~mol} \%$ broke in water, and those with a St content over $80 \mathrm{~mol} \%$ showed white turbidity. Clear and flat polymer plates suitable for matrix polymers were obtained with Sample \#11 (St:NaSS = $8: 2, \mathrm{DVB}=8.32 \mathrm{wt} \%)$ and $\# 12(\mathrm{St}: \mathrm{NaSS}=7: 3, \mathrm{DVB}=8.57 \mathrm{wt} \%)$. When the ratio of 
St:NaSS is keep at 8.5:1.5, the polymer with a DVB content of $16.1-21.8$ mol\% is clear and flat.

When the ratio of St:NaSS is kept at 7.5:2.5, clear and flat polymer plates are obtained with a DVB content of $22.2 \mathrm{~mol} \%$ only (Fig. 9). Dense and clear flat polymer plates are desirable, and deformation and turbidity are undesirable for use as a polymer matrix.

In the case of MMA-AMPS-TMPTA, flat and transparent polymers are obtained for all compositions in this study, and the range of composition variation wherein it is possible to obtain a good polymer plate is greater for this copolymer than for the St-NaSS-DVB copolymer. It is difficult to compare the hydrophobicity of MMA-AMPS-TMPTA and St-NaSS-DVB directly, and the difference in the polymer shape cannot be explained using only the hydrophobicity. The significant difference between these two types of copolymers is in the structure of the cross-linking agent. The reactive vinyl group in DVB is connected to the benzene core directly, which may give rigidity to the polymer network, and the St-NaSS-DVB copolymer collapses in conditions that cause more swelling because of the low flexibility of this polymer network. The TMPTA has three reactive groups that are connected via a longer chain than is present in the other copolymer. Instead of having more functional groups in a molecule, the flexibility is enough for swelling in conditions that are more hydrophilic. However, this higher 
flexibility causes aggregation of the nanoparticles in the polymer. Although the range for suitable composition is narrow for the St-NaSS-DVB copolymer, the rigidity and lower flexibility of this copolymer induces well-dispersed nanoparticles without aggregation.

\section{Figure 9}

\subsection{Introducing the zinc sulfide into the St-NaSS-DVB matrix polymer}

Using suitable polymer plates (Sample \#19, \#24), the zinc ion loading treatment is applied. There was no significant change in the appearance of the polymer plates during the zinc ion absorption and sulfurization process. A picture of the St-NaSS-DVB/ZnS composite polymer is shown in Figure 10. The composite polymer is flat, colorless, and transparent without any turbidity. The amount of zinc sulfide is found from TGA, and the TG curve from Sample \#19 is shown in Figure 11. The thermal degradation commences at $100^{\circ} \mathrm{C}$ and reaches a constant around $600^{\circ} \mathrm{C}$. A higher temperature is required for this copolymer than in the case of MMA-AMPS-TMPTA, and a significant difference in the TG curves between the matrix polymer and the composite is confirmed, although the reason for this difference is not clear at this time. The equivalent ratio of 
the embedded zinc amount to the cation-exchange capacity of the matrix polymer is around $80 \%$, which is a comparable ratio to that for the MMA-AMPTS-TMPTA copolymer (Table 3).

\section{Figure 10}

\section{Table 3}

No aggregated zinc sulfide particles were observed. Although no peaks are distinguished in the XRD pattern (Fig. 12), the peak pattern of zinc oxide [45] is detected in the oxidized composite (Fig. 13).

\section{Figure12}

\section{Figure13}

The presence of nanoparticles is confirmed in TEM observations of the composite polymer of Sample \#19 (Fig. 14). The sizes of the particles are estimated from this TEM image to be $4-5 \mathrm{~nm}$ in diameter. The nanosized particles generated in the polymer matrix are too small to diffract X-rays. The primary particles of zinc sulfide dispersed in 
the polymer matrix are obtained by the sulfurization of absorbed zinc ions and, because the ion-exchange group and the procedure in the St-NaSS-DVB copolymer matrix is identical to that of the MMA-AMPS-TMPTA copolymer matrix, zinc sulfide generation in this matrix is assumed. The composite obtained is colorless, clear and without deformation. The refractive indices of these composites (Table 3) are measured with an Abbe refractometer with the value of the base polymer and the calculated value from the zinc sulfide content obtained using the Lorentz-Lorenz equation [48] $\left(n_{\mathrm{ZnS}}=2.37\right.$, $\left.d \mathrm{Zns}=4.0,[49], d_{\text {polymer }}=1.1\right)$. The refractive index of each composite increase with the introduction of zinc sulfide. We infer that the measured values from the composites are larger than the calculated value of zinc sulfide because of the presence of zinc sulfide nanoparticles on the surface of the composites.

\section{Figure14}

The increase in the refractive index of the composites compared with the matrix polymer, though small, is significant to show that zinc sulfide has an obvious effect on the composite refractive index. It is therefore possible to calculate the refractive index of mixed materials, such as nanocomposites, as a volume fraction of each of the components based on the Lorentz-Lorenz equation. 


\section{Conclusions}

MMA-AMPS-TMPTA and St-NaSS-DVB copolymers are synthesized as a polymer matrix, and $\mathrm{ZnS}$ particles are generated in the polymer networks. In the MMA-AMPS-TMPTA copolymer matrix, the $\mathrm{ZnS}$ nanoparticles aggregate. Individual ZnS particles are observed in the St-NaSS-DVB copolymer matrixes with particular composition ratios, and these composite polymers show slightly higher refractive indices owing to the embedded $\mathrm{ZnS}$ particles. In the results shown in this report, the amount of embedded $\mathrm{ZnS}$ is too small to modulate the refractive index enough for practical application. However, the homogeneously dispersed nanoparticles in the polymer are useful for quantum dot and optical devices.

\section{Acknowledgements}

This work was partially supported by Core Research for Evolutional Science and Technology (CREST) of the Japan Science and Technology Agency (JST).

\section{References}

[1] A.J. Nozik, Physica E 14 (2002) 115 - 120. 
[2] I. Robel, V. Subramanian, M. Kuno, P. V. Kamat, J. Am. Chem. Soc., 128( 2006) 238 - 2393.

[3] J. B. Sambur, T. Novet, B. A. Parkinson, Science, 330 (2010) $63-66$.

[4] A.R. Kovsha, N.A. Maleeva, A.E. Zhukova, S.S. Mikhrina, A.P. Vasil'eva, E.A. Semenovaa, Yu. M. Shernyakova, M.V. Maximova, D.A. Livshitsa, V.M. Ustinova, N.N. Ledentsova,b, D. Bimbergb, Zh.I. Alferova, J. Cryst. Growth 251 (2003) 729 - 736.

[5] L. Pavesi, L. D. Negro, C. Mazzoleni, G. Franzò, F. Priolo, Nature, 408 (2000) 440 - 444.

[6] P. Lodahl1, A. F. Driel, I. S. Nikolaev, A. Irman, K. Overgaag, D. Vanmaekelbergh, W. L. Vos Nature, 430 (2004) $654-657$.

[7] S. Strauf, K. Hennessy, M. T. Rakher, Y. S. Choi, A. Badolato, L. C. Andreani, E. L. Hu, P. M. Petroff, D. Bouwmeester, Phys. Rev. Lett., 96 (2006) 127404.

[8] H. Mattoussi, J. M. Mauro, E. R. Goldman, G. P. Anderson, V. C. Sundar, F. V. Mikulec, M. G. Bawendi, J. Am. Chem. Soc., 122 (2000) 12142 - 12150.

[9] B. Sun, W.Xie, G. Yi, D. Chen, Y. Zhou, J. Cheng, J. Immunological Methods 249 (2001) $85-89$.

[10] X. Cao, C. M. Li, H. Bao, Q. Bao, H. Dong, Chem. Mater., 19 (2007) 3773 - 3779.

[11] B. O. Dabbousi, J. Rodriguez-Viejo, F. V. Mikulec, J. R. Heine, H. Mattoussi, R. Ober,K. F. Jensen, M. G. Bawendi*, J. Phys. Chem. B, 101 (1997) 9463 - 9475.

[12] P. Atkinson, M.B. Ward, S. P. Bremner, D. Anderson, T. Farrow, G. A. C. Jones, A. J. Shields, D.A. Ritchie, Physica E, 32 (2006) $21-24$. 
[13] J. Valenta, R. Juhasz, J. Linnros, J. Luminescence, 98 (2002) 15 - 22.

[14] H. Heidemeyer, C. Muller, O.G. Schmidt, Physica E, 23 (2004) 237 - 242.

[15] G. S. Solomon, J. A. Trezza, A. F. Marshall, J. S. Harris, Jr., Phys. Rev. Lett., 76 (1996) 952 955.

[16] C. Jiang, T. Kawazu, S. Kobayashi, H. Sakaki, J. Cryst. Growth, $301-302$ (2007) $828-832$.

[17] S. Franchi, G. Trevisi, L. Seravalli, P. Frigeri, Prog. Cryst. Growth Charact. Mat., 47 (2003) $166 \mathrm{e} 195$.

[18] V. Zwiller, M. Pistol, D. Hessman, R. Cederström, W. Seifert, L. Samuelson, Phys. Rev. B, 59 (1999) $5021-5025$.

[19] R. Xie, M. Rutherford, X. Peng, J. Am. Chem. Soc.,131 (2009) 5691 - 5697.

[20] Z. A. Peng, X. Peng, J. Am. Chem. Soc., 123 (2001) 183 - 184.

[21] S. G.Thoma, M. Ciftcioglu, D. M.Smith, Powder Technol., 68 (1991) $71-78$.

[22] N. Mandzy, E. Grulke,T. Druffel, Powder Technol., 160 (2005) 121 - 126.

[23] C. Lü, Z. Cui, Y. Wang, Z. Li, C. Guan, B. Yang, J. Shen, J. Mater. Chem., 13 (2003) 2189 - 2195.

[24] J. L. H. Chau, Y. Lin, A. Li, W. Su, K. Chang, L. Hsu, T. Li, Mater. Lett., 61 (2007) 2908 - 2910.

[25] M. Ochi, D.Nii, Y.Suzuki, M. Harada, J. Mater. Sci., 45 (2010) 2655 - 2661.

[26] Z. Lin, Y. Cheng, H. Lü, L. Zhang, B. Yang, Polym., 51 (2010) 5424e5431.

[27] R. J. Nussbaumer, W. R. Caseri, P. Smith, T. Tervoort, Macromol. Mater. Eng., 288 (2003) 44 - 49. 
[28] C. Guan, C. Lu, Y. Liu, B. Yang, J. Appl. Polym. Sci. 102 (2006) 1631 - 1636.

[29] C. Lü, Y. Cheng, Y. Liu, F. Liu, B. Yang, Adv. Mater., 18 (2006) 1188 - 1192.

[30] K. P. Velikov, A. Blaaderen, Langmuir, 17 (2001) 4779 - 4786.

[31] Y. Yang, J. Huang, S. Liu, J. Shen, J. Mater. Chem., 7 (1997) 131 - 133.

[32] W. Tang, D. C. Cameron, Thin Solid Films 280 (1996) 221 - 226.

[33] H. Yang, P. H. Holloway, J. Phys. Chem. B, 107 (2003) 9705 - 9710.

[34] M. Sabzi, S. M. Mirabedini, J. Zohuriaan-Mehr, M. Atai, Prog. Org. Coatings 65 (2009) 222 - 228.

[35] K. Xu., S. Zhou. L. Wu, J. Mater. Sci. 44 (2009) 1613 - 1621.

[36] Y. Wang, D. Zhang, L. Shi, L. Li, J. Zhang, Mat. Chem. Phys. 110 (2008) 463 - 470.

[37] R. J. Nussbaumer, W. R. Caseri, P. Smith, T. Tervoort, Macromol. Mater. Eng.,288 (2003) 44 - 49.

[38] A. Convertino, G.Leo, M. Tamborra, C. Sciancalepore, M. Striccoli, M.L. Curri, A. Agostiano, Sensors and Actuators B, 126 (2007) $138-143$.

[39] R. F. Ziolo, E. P. Giannelis, B. A. Weinstein, M. P. O'Horo, B. N. Ganguly, V. Mehrotra, M. W. Russell, D. R. Huffman, Science, 257 (1992) 219 - 223.

[40] K. S. V. Krishna Rao, Chang-Sik Ha, Polym. Bull. 62 (2009) 167 - 181

[41] S. ÇAVUŞ, J. Polym. Sci. B Polym. Phys. 48 (2010) 2497 - 2508

[42] V. K. Tikku, G. Biswas, R. S. Despande, A. B. Majali, T. K. Chaki, A. K. Bhowmick, Radiat. Phys. Chem. 45 (1995) $829-833$ 
[43] J. M. O'Reilly, R. A. Mosher, Macromol. 14 (1981) 602 - 608

[44] M.M. Nasef, N.A. Zubir, A.F. Ismail, K.Z.M. Dahlan, H. Saidi, M. Khayet, J. Pow.Sourc. 156

(2006) $200-210$

[45] H. F. McMurdie, M. C. Morris, E. H. Evans, B. Paretzkin, Ng W. Wong, L. D. Ettlinger, C. R. Hubbard, Powder Diffr., 1 (1986), 64 - 77.

[46] R. Jordan,A. Ulman, J. F. Kang, M. H. Rafailovich, J. Sokolov, J. Am. Chem. Soc., 121 (1999) 1016 $-1022$

[47] L. Xu, X. Li, M. Zhai, L. Huang, J. Peng, J. Li, G. Wei , J. Phys. Chem.B 111 (2007) 3391-3397.

[48] W. Heller, J. Phys. Chem., 69 (1965) 1123 - 1129.

[49] K. P. Velikov, A. Blaaderen, Langmuir, 17 (2001) 4779 - 4786. 
List of Figures and Tables

Fig. 1 Scheme showing the generation of matrix-mediated $\mathrm{ZnS}$ nanoparticles.

Fig. 2 IR spectra of the polymer matrices (a) MMA-AMPS-TMPTA (Sample \#6), (b) St-NaSS-DVB, and (c) protonated St-NaSS-DVB.

Fig. 3 XRD pattern of ZnS embedded in the MMA-AMPS-TMPTA polymer matrix (Sample \#6) and the pattern from wurtzite $\mathrm{ZnS}$ [45] (comparison).

Fig. 4 TEM images of nanoparticles generated in the MMA-AMPS-TMPTA polymer matrix (a),(b) Composite from Sample \#6 $($ TMPTA $=2.1$ mol\%), $(\mathrm{c})$ Composite from Sample \#7 $($ TMPTA $=3.9$ mol\%), (d) Composite from Sample \#8 (TMPTA = $6.1 \mathrm{~mol} \%)$.

Fig.5 TG thermogram of the (a) MMA-AMPS-TMPTA polymer matrix (Sample \#3) and the (b) MMA-AMPS-TMPTA/ZnS composite from Sample \#3.

Fig. 6 Ratio of the amount of embedded zinc to AMPS content as a function of the MMA:AMPS composition of the matrix copolymer. 
Fig. 7 Ratio of the embedded zinc amount to AMPS content as a function of the TMPTA content in the matrix copolymer.

Fig. 8 Physical appearance of St-NaSS-DVB copolymers at different St:NaSS composition ratios.

Fig. 9 Physical appearance of St-NaSS-DVB copolymers with different DVB contents in the matrix copolymer Top row: $\mathrm{St}: \mathrm{NaSS}=8.5: 1.5$, Bottom Row: St:NaSS = 7.5:2.5.

Fig. 10 Picture of the St-NaSS-DVB/ZnS composite of Sample \#24.

Fig. 11 TG thermogram of the (a) St-NaSS-DVB polymer matrix (Sample \#19) and the (b) St-NaSS-DVB/ZnS composite from Sample \#19.

Fig. 12 XRD pattern of the St-NaSS-DVB/ZnS composite (a) Composite from Sample \#19, (b) Composite from Sample \#24

Fig. 13 XRD patterns of oxidized St-NaSS-DVB/ZnS composites and the pattern from $\mathrm{ZnO}$ [45] (comparison) (a) Oxidized composite from Sample \#19 with ZnS, (b) Oxidized composite from Sample \#24

Fig. 14 TEM image of $\mathrm{ZnS}$ nanoparticles in the St-NaSS-DVB/ZnS composite from Sample \#24. 
Table 1 Composition ratios of the MMA-AMPS-TMPTA matrix copolymer feed.

Table 2 Composition ratios of the St-NaSS-DVB matrix copolymer feed.

Table 3 Measured and calculated refractive indices of the St-NaSS-DVB/ZnS composites and the matrix copolymers. 
Table 1 Composition ratios of the MMA-AMPS-TMPTA matrix copolymer feed.

\begin{tabular}{|c|c|c|c|c|c|c|c|}
\hline \multirow[b]{2}{*}{ Sample } & MMA & AMPS & TMPTA & \multirow{2}{*}{$\begin{array}{c}\text { Monomer } \\
\text { concentration } \\
\text { wt } \%\end{array}$} & \multirow{3}{*}{$\begin{array}{c}\text { MMA:AMPS ratio } \\
(\mathrm{mol})\end{array}$} & \multirow{3}{*}{$\begin{array}{r}\begin{array}{c}\text { TMPTA } \\
(w t \%)\end{array} \\
9.08\end{array}$} & \multirow[b]{2}{*}{$\begin{array}{c}\text { Cation-exchange site } \\
(\mathrm{meq} / \mathrm{g})\end{array}$} \\
\hline & \multicolumn{3}{|c|}{$\begin{array}{l}\text { feed in copolymer* } \\
(\mathrm{mol} \%)\end{array}$} & & & & \\
\hline$\# 1$ & $\begin{array}{l}2.00 \mathrm{~g} \\
(96.7)\end{array}$ & - & $\begin{array}{l}0.200 \mathrm{~g} \\
(3.3)\end{array}$ & 66.7 & & & 0.00 \\
\hline$\# 2$ & $\begin{array}{l}1.617 \mathrm{~g} \\
(86.7)\end{array}$ & $\begin{array}{l}0.380 \mathrm{~g} \\
(9.8)\end{array}$ & $\begin{array}{l}0.200 \mathrm{~g} \\
(3.6)\end{array}$ & 66.6 & $9: 1$ & 9.10 & 0.84 \\
\hline$\# 3$ & $\begin{array}{l}1.316 \mathrm{~g} \\
(76.9)\end{array}$ & $\begin{array}{c}0.680 \\
(19.2)\end{array}$ & $\begin{array}{l}0.200 \mathrm{~g} \\
(3.9)\end{array}$ & 66.6 & $8: 2$ & 9.43 & 1.49 \\
\hline \#4 & $\begin{array}{l}1.062 \mathrm{~g} \\
(67.1)\end{array}$ & $\begin{array}{l}0.940 \\
(28.7)\end{array}$ & $\begin{array}{l}0.200 \mathrm{~g} \\
(4.3)\end{array}$ & 66.7 & $7: 3$ & 9.08 & 2.06 \\
\hline$\# 5$ & $\begin{array}{l}0.837 \mathrm{~g} \\
(57.1)\end{array}$ & $\begin{array}{l}1.16 \\
(38.3)\end{array}$ & $\begin{array}{l}0.200 \mathrm{~g} \\
(4.6)\end{array}$ & 66.6 & $6: 4$ & 9.11 & 2.55 \\
\hline \#6 & $\begin{array}{l}1.241 \mathrm{~g} \\
(77.4)\end{array}$ & $\begin{array}{l}0.680 \\
(20.5)\end{array}$ & $\begin{array}{l}0.100 \mathrm{~g} \\
(2.1)\end{array}$ & 64.8 & $8: 2$ & 4.95 & 1.62 \\
\hline$\# 7$ & $\begin{array}{l}1.316 \mathrm{~g} \\
(76.9)\end{array}$ & $\begin{array}{c}0.680 \\
(19.2)\end{array}$ & $\begin{array}{l}0.200 \mathrm{~g} \\
(3.9)\end{array}$ & 66.6 & $8: 2$ & 9.3 & 1.49 \\
\hline$\# 8$ & $\begin{array}{l}1.241 \mathrm{~g} \\
(74.3)\end{array}$ & $\begin{array}{c}0.680 \\
(19.7)\end{array}$ & $\begin{array}{l}0.300 \mathrm{~g} \\
(6.1)\end{array}$ & 66.9 & $8: 2$ & 13.5 & 1.48 \\
\hline$\# 9$ & $\begin{array}{l}1.241 \mathrm{~g} \\
(72.8)\end{array}$ & $\begin{array}{l}0.680 \\
(19.3)\end{array}$ & $\begin{array}{l}0.400 \mathrm{~g} \\
(7.9)\end{array}$ & 67.8 & $8: 2$ & 17.2 & 1.41 \\
\hline
\end{tabular}

* Monomer mixtures were dissolved in $1 \mathrm{~cm}^{3}$ of DMSO 
Table 2 Composition ratios of the St-NaSS-DVB matrix copolymer feed.

\begin{tabular}{|c|c|c|c|c|c|c|c|c|}
\hline Sample & St & $\begin{array}{c}\mathrm{NaSS} \\
\mathrm{din} \text { copoly } \\
(\mathrm{mol} \%)\end{array}$ & ner & $\begin{array}{c}\mathrm{DMSO} \\
\left(\mathrm{cm}^{3}\right)\end{array}$ & $\begin{array}{c}\text { Monomer } \\
\text { concentration } \\
(\mathrm{wt} \%)\end{array}$ & $\begin{array}{c}\text { St:NaSS ratio } \\
(\mathrm{mol})\end{array}$ & $\begin{array}{l}\text { DVB } \\
(\mathrm{wt} \%) \\
\end{array}$ & $\begin{array}{c}\text { Cation-exchange site } \\
(\mathrm{meq} / \mathrm{g})\end{array}$ \\
\hline$\# 10$ & $\begin{array}{l}1.654 \mathrm{~g} \\
(83.5)\end{array}$ & $\begin{array}{l}0.360 \mathrm{~g} \\
(9.2)\end{array}$ & $\begin{array}{l}0.183 \mathrm{~g} \\
(7.4)\end{array}$ & 2 & 50.0 & $9: 1$ & 8.32 & 0.89 \\
\hline \#11 & $\begin{array}{l}1.354 \mathrm{~g} \\
(73.8)\end{array}$ & $\begin{array}{l}0.660 \mathrm{~g} \\
(18.2)\end{array}$ & $\begin{array}{l}0.183 \mathrm{~g} \\
(8.0)\end{array}$ & 3 & 40.0 & $8: 2$ & 8.32 & 1.45 \\
\hline \#12 & $\begin{array}{l}1.091 \mathrm{~g} \\
(65.3)\end{array}$ & $\begin{array}{l}0.860 \mathrm{~g} \\
(26.0)\end{array}$ & $\begin{array}{l}0.183 \mathrm{~g} \\
(8.7)\end{array}$ & 5 & 28.0 & $7: 3$ & 8.57 & 1.94 \\
\hline \#13 & $\begin{array}{l}0.927 \mathrm{~g} \\
(60.3)\end{array}$ & $\begin{array}{l}0.920 \mathrm{~g} \\
(30.2)\end{array}$ & $\begin{array}{l}0.183 \mathrm{~g} \\
(9.5)\end{array}$ & 5 & 27.0 & $6.5: 3.5$ & 9.00 & 2.19 \\
\hline$\# 14$ & $\begin{array}{l}0.764 \mathrm{~g} \\
(52.8)\end{array}$ & $\begin{array}{l}1.060 \mathrm{~g} \\
(37.0)\end{array}$ & $\begin{array}{l}0.183 \mathrm{~g} \\
(10.1)\end{array}$ & 5 & 26.7 & $6: 4$ & 9.11 & 0.44 \\
\hline$\# 15$ & $\begin{array}{l}0.600 \mathrm{~g} \\
(43.4)\end{array}$ & $\begin{array}{l}1.260 \mathrm{~g} \\
(46.0)\end{array}$ & $\begin{array}{l}0.183 \mathrm{~g} \\
(10.6)\end{array}$ & 5 & 27.1 & $5: 5$ & 8.95 & 2.98 \\
\hline$\# 16$ & $\begin{array}{l}0.445 \mathrm{~g} \\
(33.6)\end{array}$ & $\begin{array}{l}1.450 \mathrm{~g} \\
(55.3)\end{array}$ & $\begin{array}{l}0.183 \mathrm{~g} \\
(11.0)\end{array}$ & 6 & 23.9 & $4: 6$ & 8.80 & 3.37 \\
\hline \#17 & $\begin{array}{l}0.291 \mathrm{~g} \\
(23.0)\end{array}$ & $\begin{array}{l}1.640 \mathrm{~g} \\
(65.5)\end{array}$ & $\begin{array}{l}0.183 \mathrm{~g} \\
(11.6)\end{array}$ & 6 & 24.3 & $2.5: 7.5$ & 8.65 & 3.74 \\
\hline \#18 & $\begin{array}{l}0.145 \mathrm{~g} \\
(12.0)\end{array}$ & $\begin{array}{l}1.820 \mathrm{~g} \\
(75.9)\end{array}$ & $\begin{array}{l}0.183 \mathrm{~g} \\
(12.1)\end{array}$ & 7 & 21.8 & $1: 9$ & 8.51 & 4.09 \\
\hline \#19 & $\begin{array}{l}1.073 \mathrm{~g} \\
(71.1)\end{array}$ & $\begin{array}{l}0.380 \mathrm{~g} \\
(12.7)\end{array}$ & $\begin{array}{l}0.304 \mathrm{~g} \\
(16.1)\end{array}$ & 3 & 34.7 & $8.5: 1.5$ & 17.3 & 1.04 \\
\hline$\# 20$ & $\begin{array}{l}0.991 \mathrm{~g} \\
(66.4)\end{array}$ & $\begin{array}{l}0.350 \mathrm{~g} \\
(11.8)\end{array}$ & $\begin{array}{l}0.406 \mathrm{~g} \\
(21.8)\end{array}$ & 3 & 34.6 & $8.5: 1.5$ & 23.2 & 0.97 \\
\hline$\# 21$ & $\begin{array}{l}0.945 \mathrm{~g} \\
(62.3)\end{array}$ & $\begin{array}{l}0.330 \mathrm{~g} \\
(11.0)\end{array}$ & $\begin{array}{l}0.507 \mathrm{~g} \\
(26.7)\end{array}$ & 2 & 44.8 & $8.5: 1.5$ & 28.5 & 0.89 \\
\hline \#22 & $\begin{array}{l}0.627 \mathrm{~g} \\
(40.5)\end{array}$ & $\begin{array}{l}0.220 \mathrm{~g} \\
(7.2)\end{array}$ & $\begin{array}{l}1.015 \mathrm{~g} \\
(52.4)\end{array}$ & 2 & 45.8 & $8.5: 1.5$ & 54.5 & 0.57 \\
\hline \#23 & $\begin{array}{l}0.836 \mathrm{~g} \\
(61.4)\end{array}$ & $\begin{array}{l}0.560 \mathrm{~g} \\
(20.8)\end{array}$ & $\begin{array}{l}0.304 \mathrm{~g} \\
(17.9)\end{array}$ & 3 & 34.0 & $7.5: 2.5$ & 17.9 & 1.59 \\
\hline \#24 & $\begin{array}{l}0.873 \mathrm{~g} \\
(59.8)\end{array}$ & $\begin{array}{l}0.520 \mathrm{~g} \\
(18.0)\end{array}$ & $\begin{array}{l}0.406 \mathrm{~g} \\
(22.2)\end{array}$ & 3 & 35.3 & $7.5: 2.5$ & 22.6 & 1.39 \\
\hline$\# 25$ & $\begin{array}{l}0.818 \mathrm{~g} \\
(55.6)\end{array}$ & $\begin{array}{l}0.490 \mathrm{~g} \\
(16.8)\end{array}$ & $\begin{array}{l}0.507 \mathrm{~g} \\
(27.6)\end{array}$ & 3 & 35.5 & $7.5: 2.5$ & 27.9 & 1.30 \\
\hline \#26 & $\begin{array}{l}0.545 \mathrm{~g} \\
(35.8)\end{array}$ & $\begin{array}{l}0.330 \mathrm{~g} \\
(10.9)\end{array}$ & $\begin{array}{l}1.015 \mathrm{~g} \\
(53.5)\end{array}$ & 3 & 36.4 & 7.5:2.5 & 53.7 & 0.84 \\
\hline
\end{tabular}


Table 3 Measured and calculated refractive indices of the St-NaSS-DVB/ZnS composites and the matrix copolymers.

\begin{tabular}{lcccccc}
\hline Sample & St:NaSS ratio & $\begin{array}{c}\text { Embedded Zn } \\
\text { to AMPS ratio } \\
\text { (eq. \%) }\end{array}$ & $\begin{array}{c}\text { Embedded ZnS } \\
\text { (mg / g-Polymer) }\end{array}$ & \multicolumn{3}{c}{ Refractive index } \\
Matrix copolymer & Composite \\
F19 & $8.5: 1.5$ & 84.8 & 43 & & Found & Calcd. \\
$\# 24$ & $7.5: 2.5$ & 78.2 & 53 & 1.575 & 1.584 & 1.582 \\
\hline
\end{tabular}



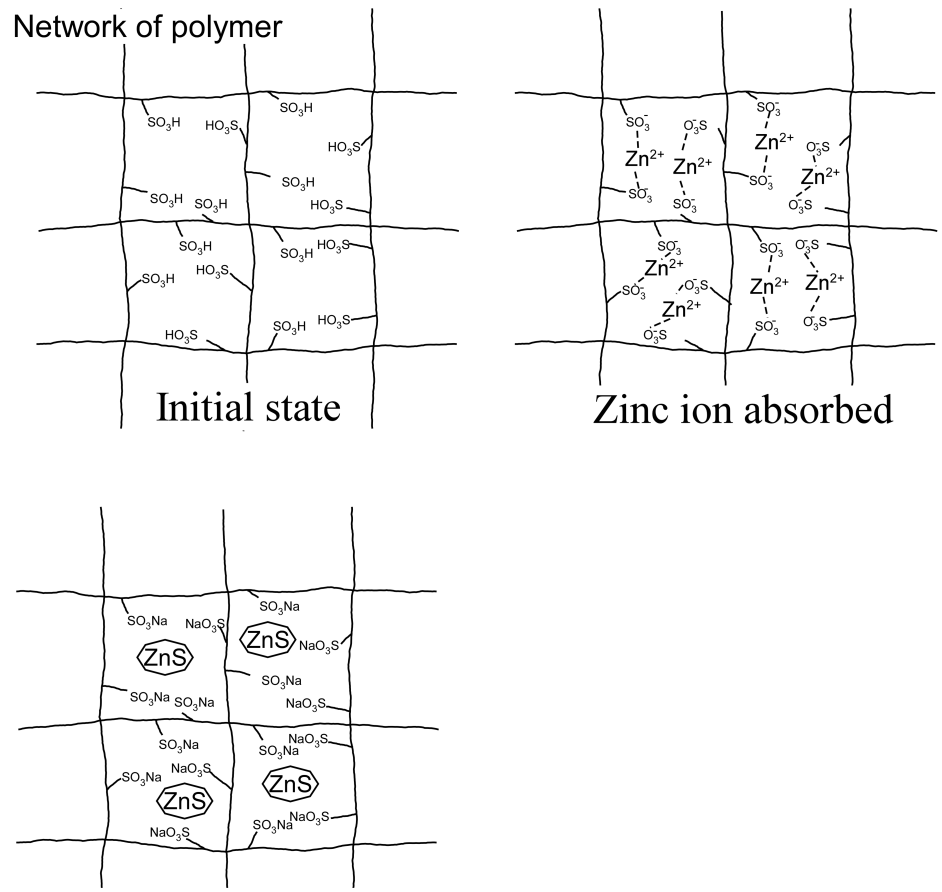

Nano deposition of zinc sulfide 
Figure 2

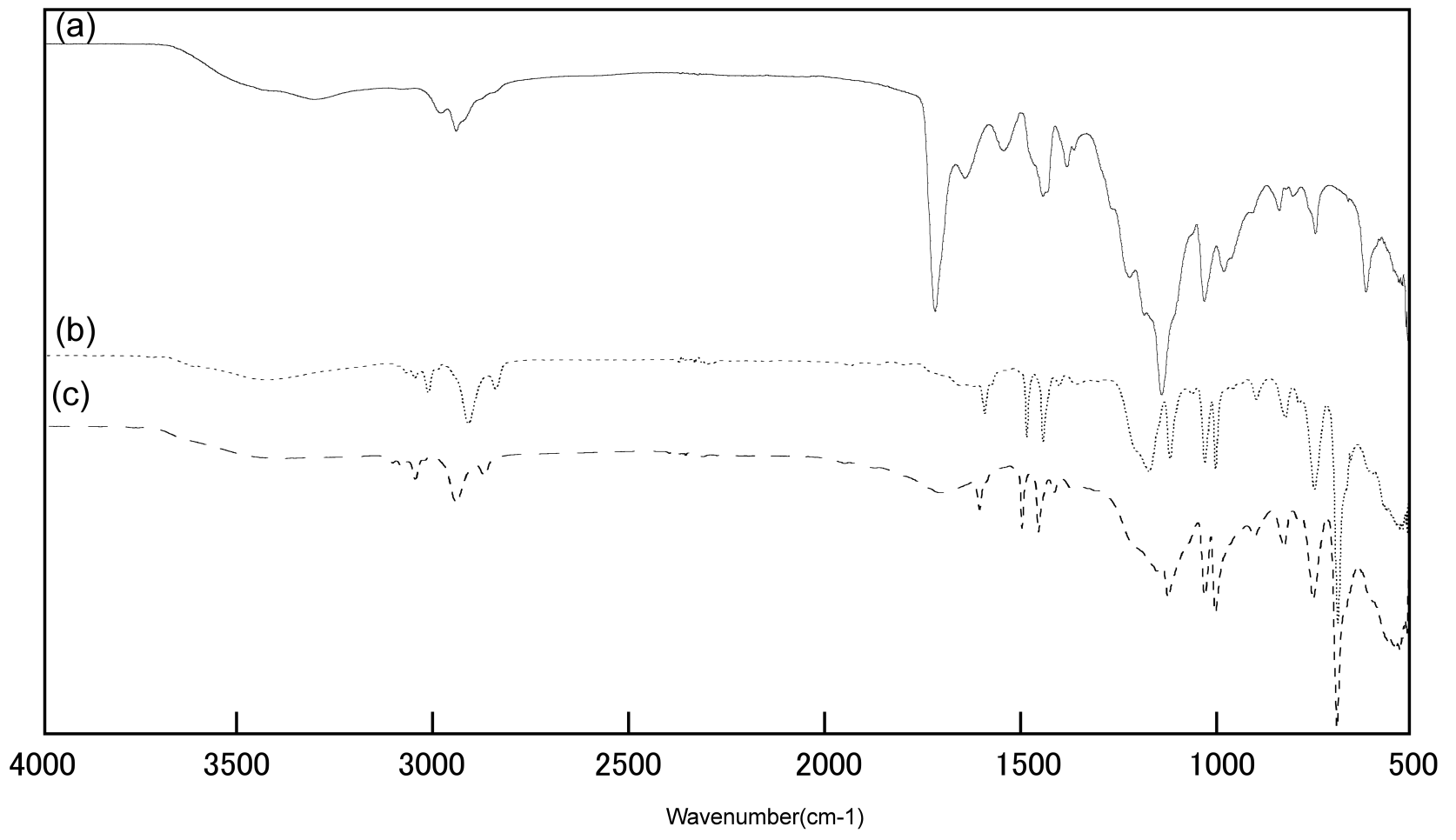




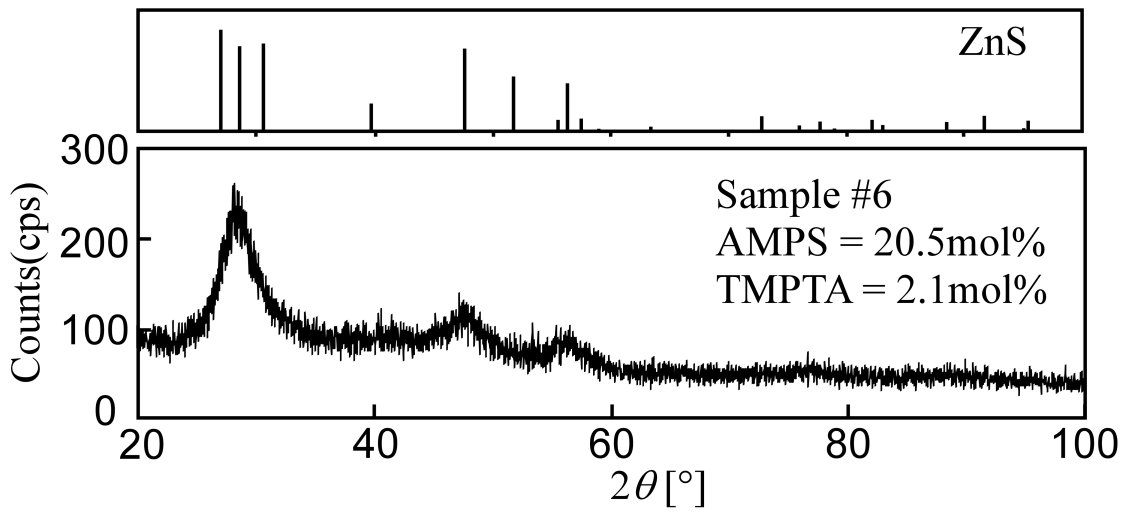


(a) Sample \#6

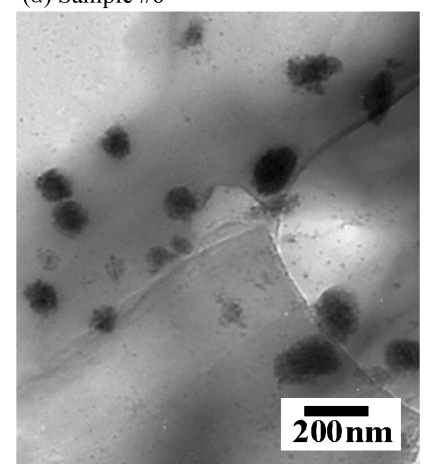

(c) Sample \#7

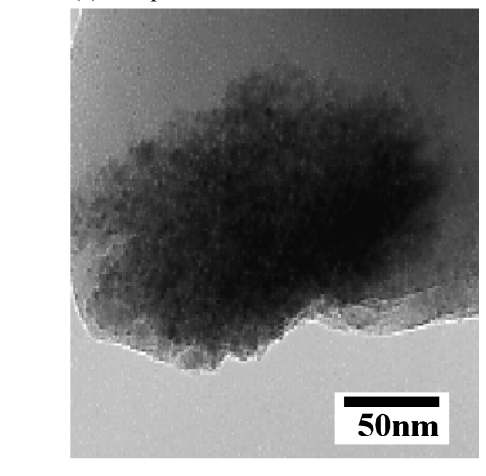

(b) Sample \#6

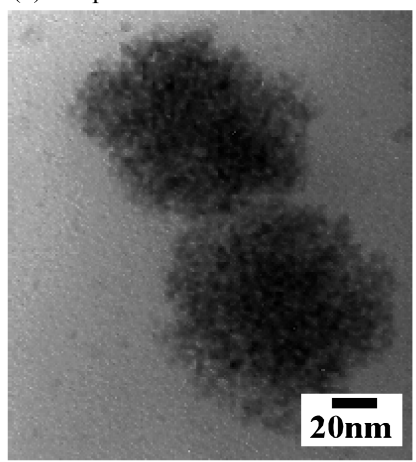

(d) Sample \#8

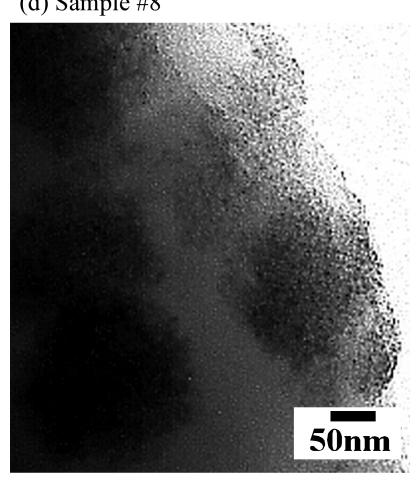

Figure 4

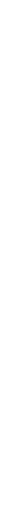


Figure 5

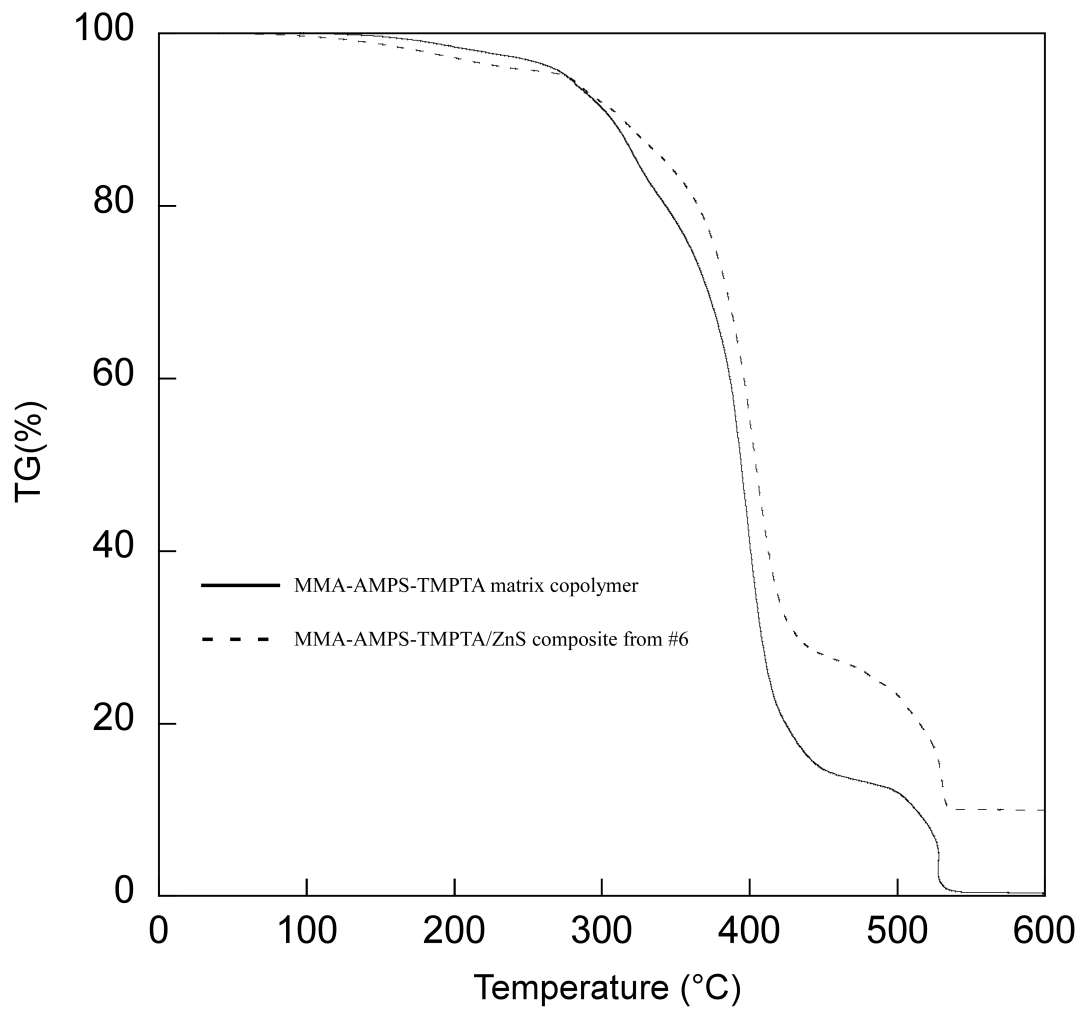


Figure 6

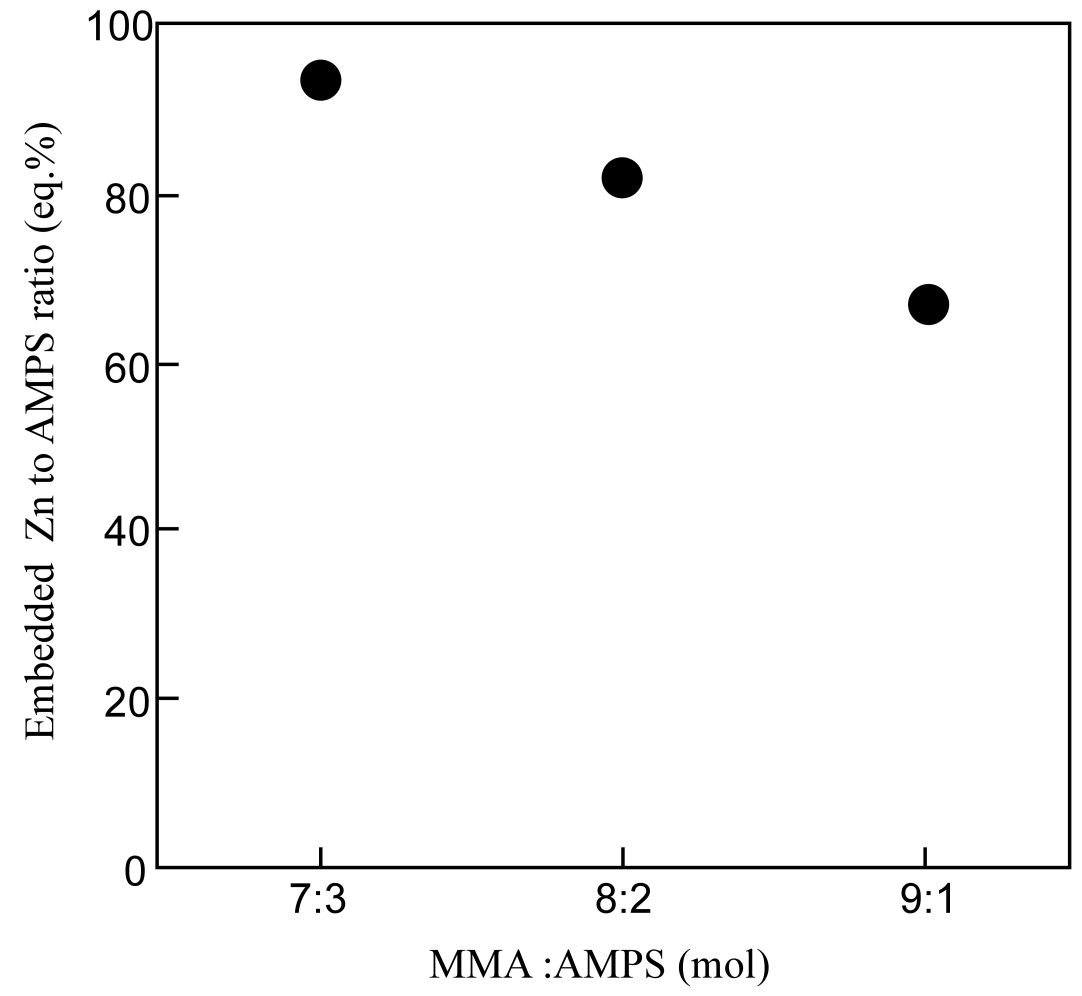




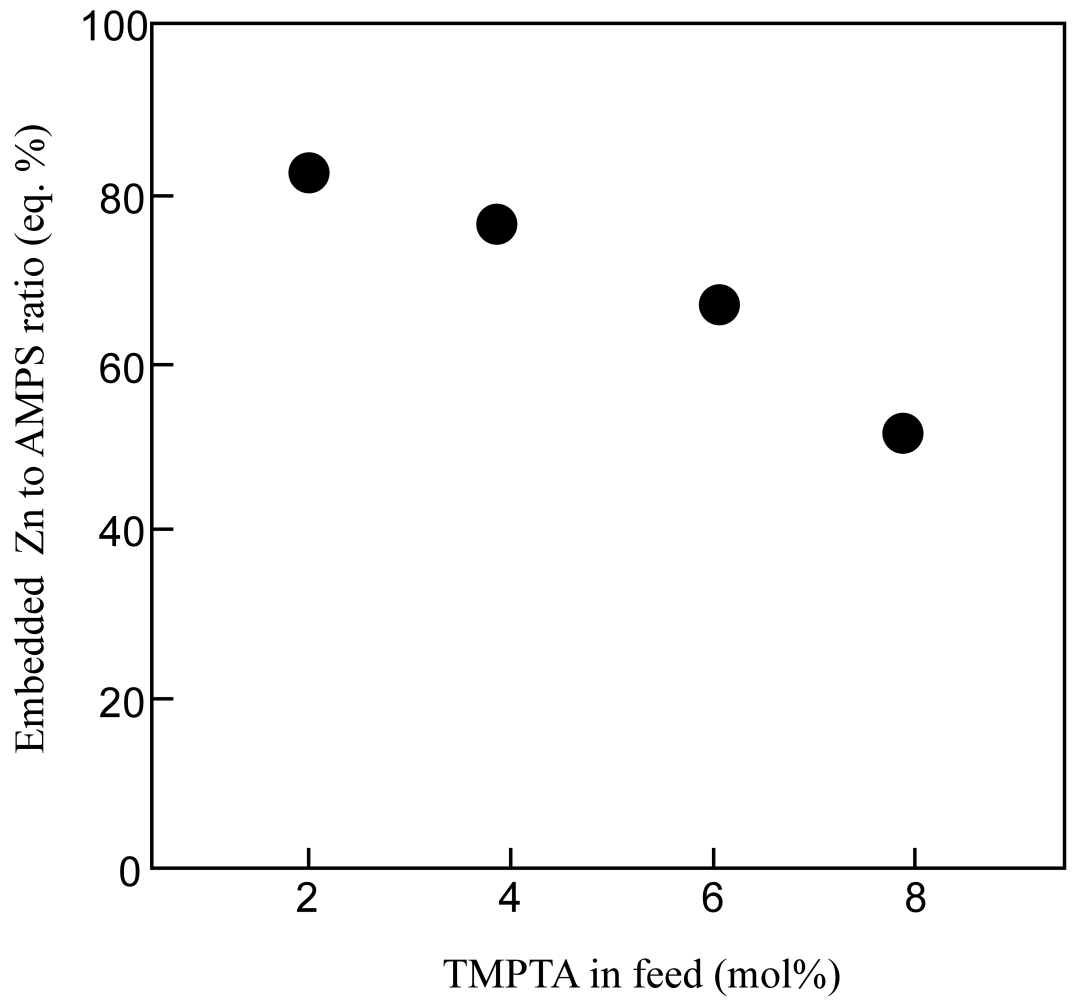




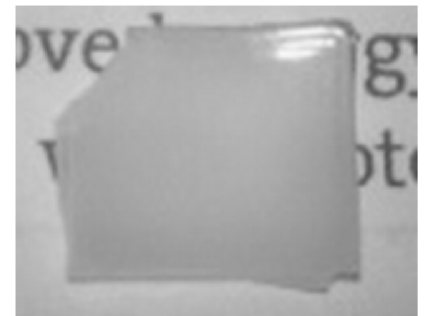

Sample \#10

St:NaSS=9:1

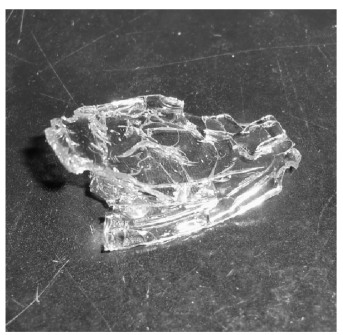

Sample \#15

$\mathrm{St}: \mathrm{NaSS}=5: 5$

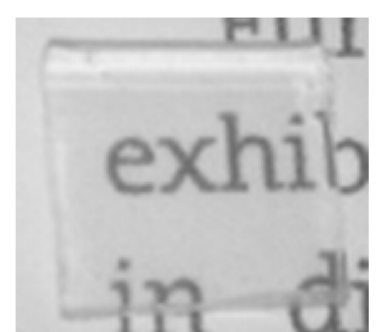

Sample \#11

$\mathrm{St}: \mathrm{NaSS}=8: 2$

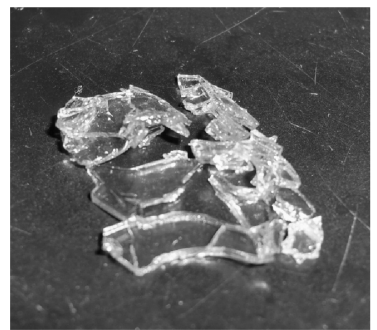

Sample \#16

$\mathrm{St}: \mathrm{NaSS}=4: 6$

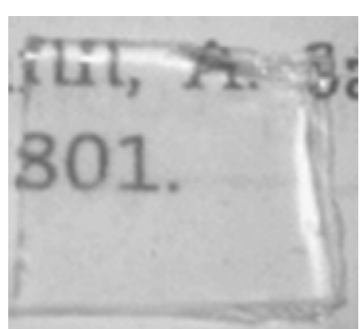

Sample \#12

St:NaSS $=7: 3$

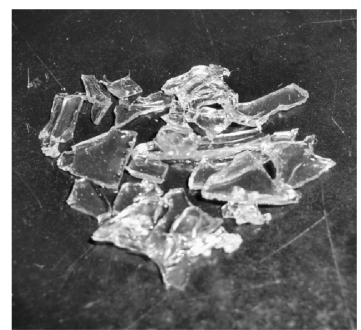

Sample \#17

$\mathrm{St}: \mathrm{NaSS}=2.5: 7.5$

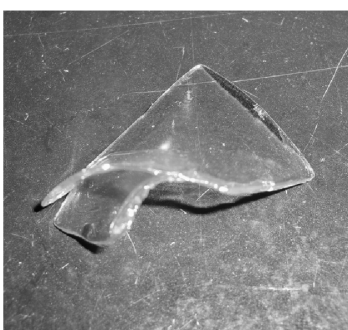

Sample \#13

St:NaSS=6.5:3.5

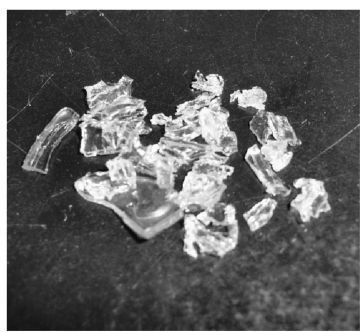

Sample \#18

St:NaSS=1:9

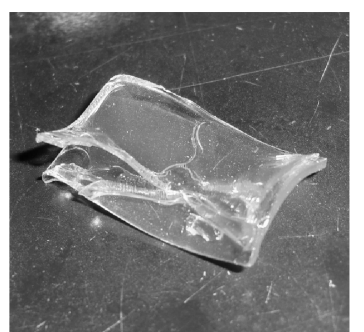

Sample \#14

$\mathrm{St}: \mathrm{NaSS}=6: 4$ 
St:NaSS $=8.5: 1.5$

oreclaim an ' aim an end to $t$
it dogmas. tl şmas, that for

Sample \#19

DVB $=16.1 \mathrm{~mol} \%$

St:NaSS $=7.5: 2.5$

a new age. Hom scliools fail too our adversaries

Sample \#23

DVB $=17.9 \mathrm{~mol} \%$

Sample \#20

DVB $=21.8 \mathrm{~mol} \%$

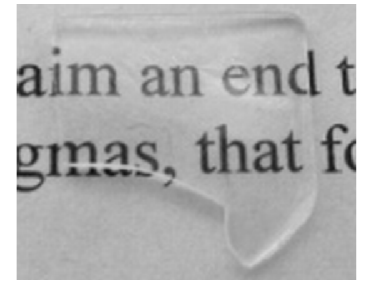

Sample \#24

DVB $=22.2 \mathrm{~mol} \%$

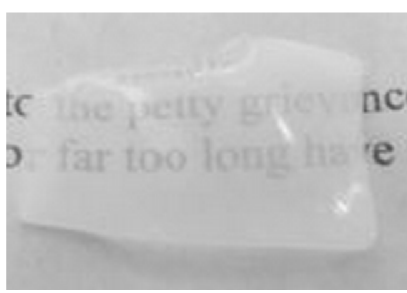

Sample \#21

DVB $=26.7 \mathrm{~mol} \%$

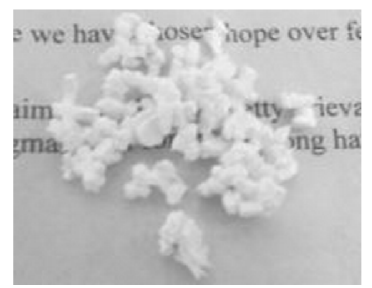

Sample \#25

DVB $=27.6 \mathrm{~mol} \%$ grievances and false promi

ng sur polit

Sample \#22

$\mathrm{DVB}=52.4 \mathrm{~mol} \%$

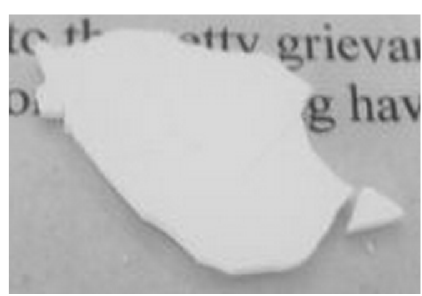

Sample \#26

$\mathrm{DVB}=53.5 \mathrm{~mol} \%$ 
Figure 10

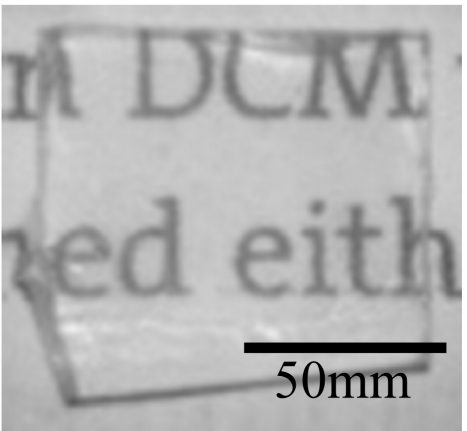




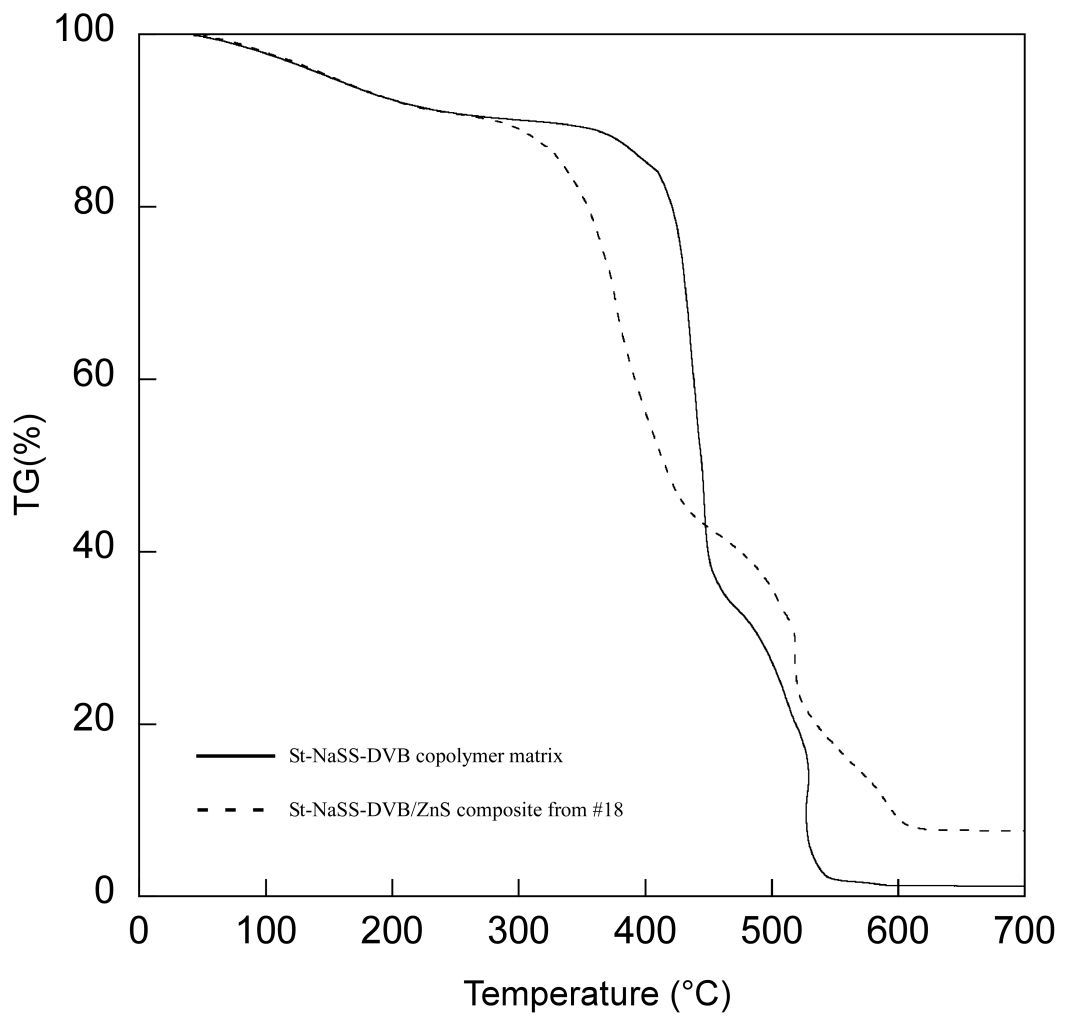



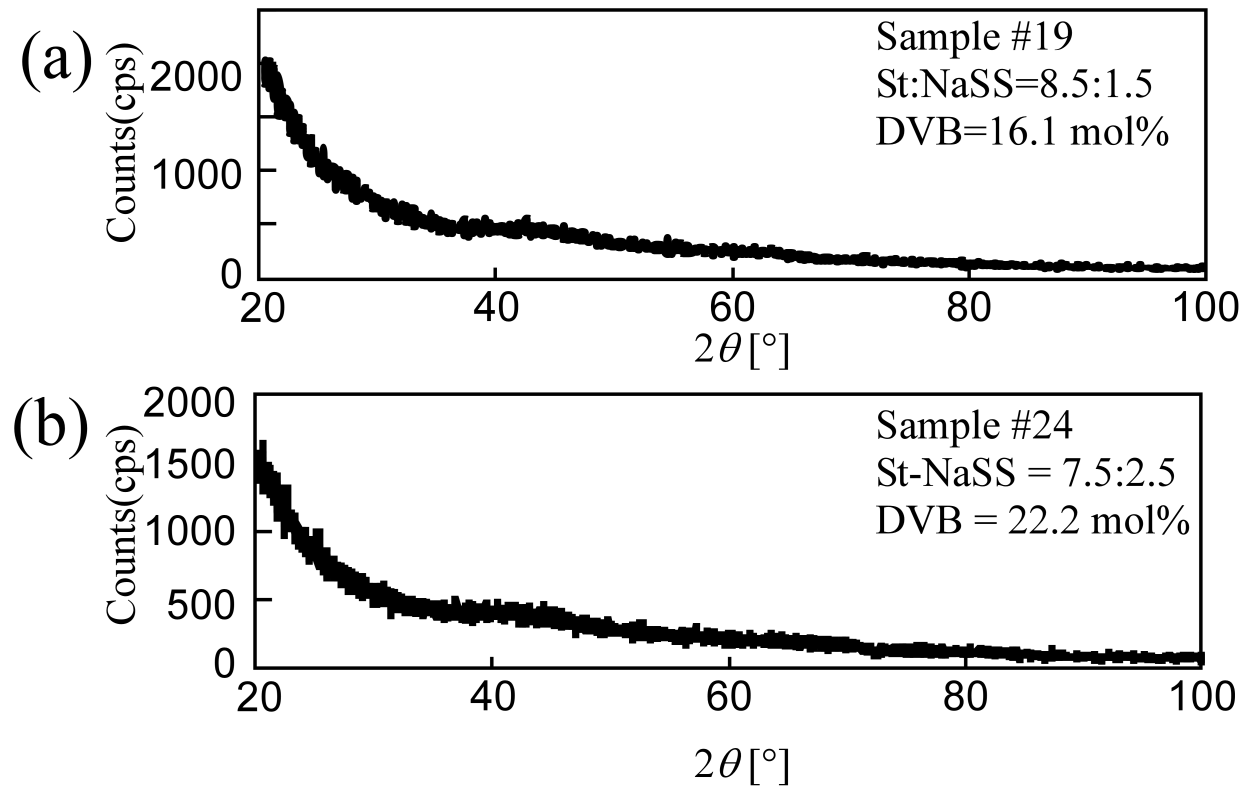


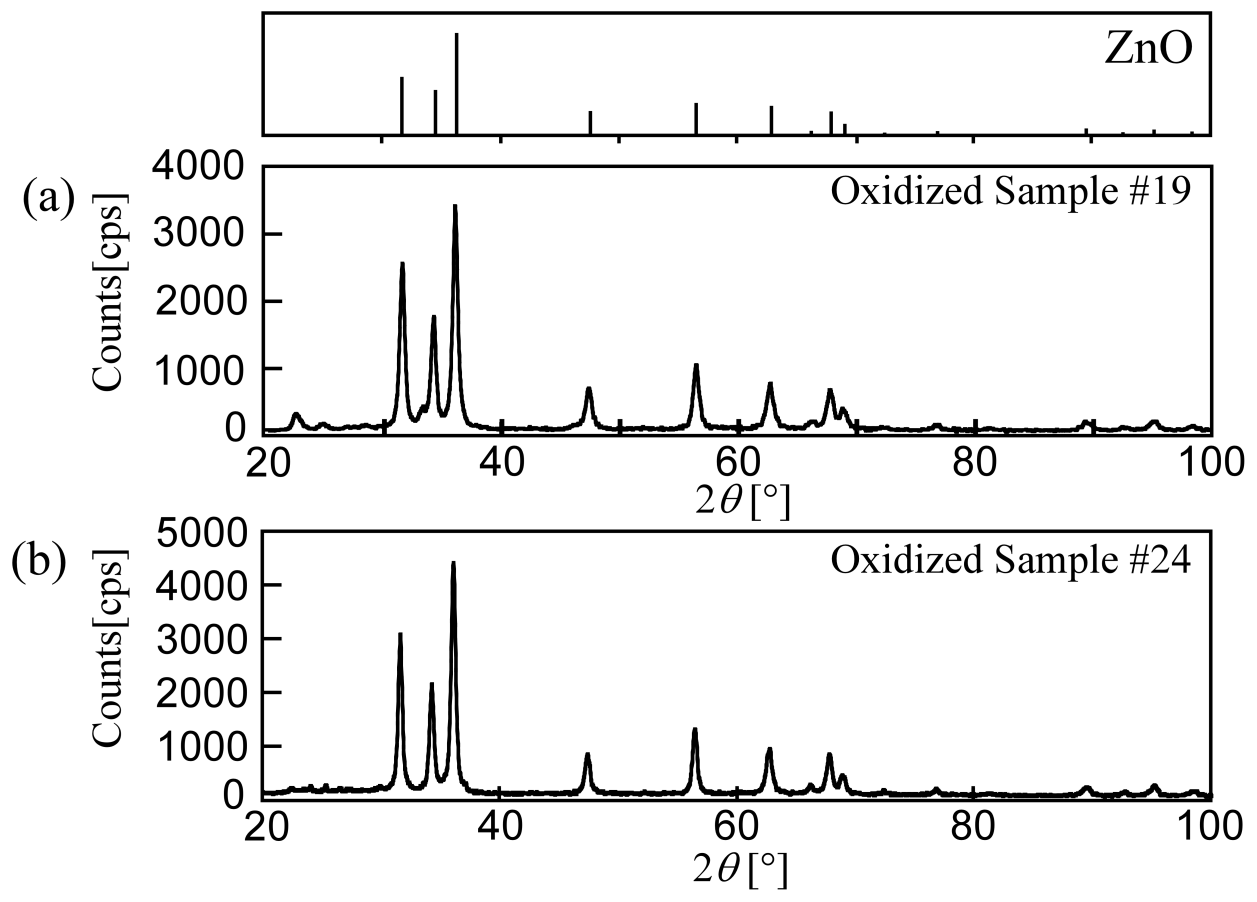


Figure 14

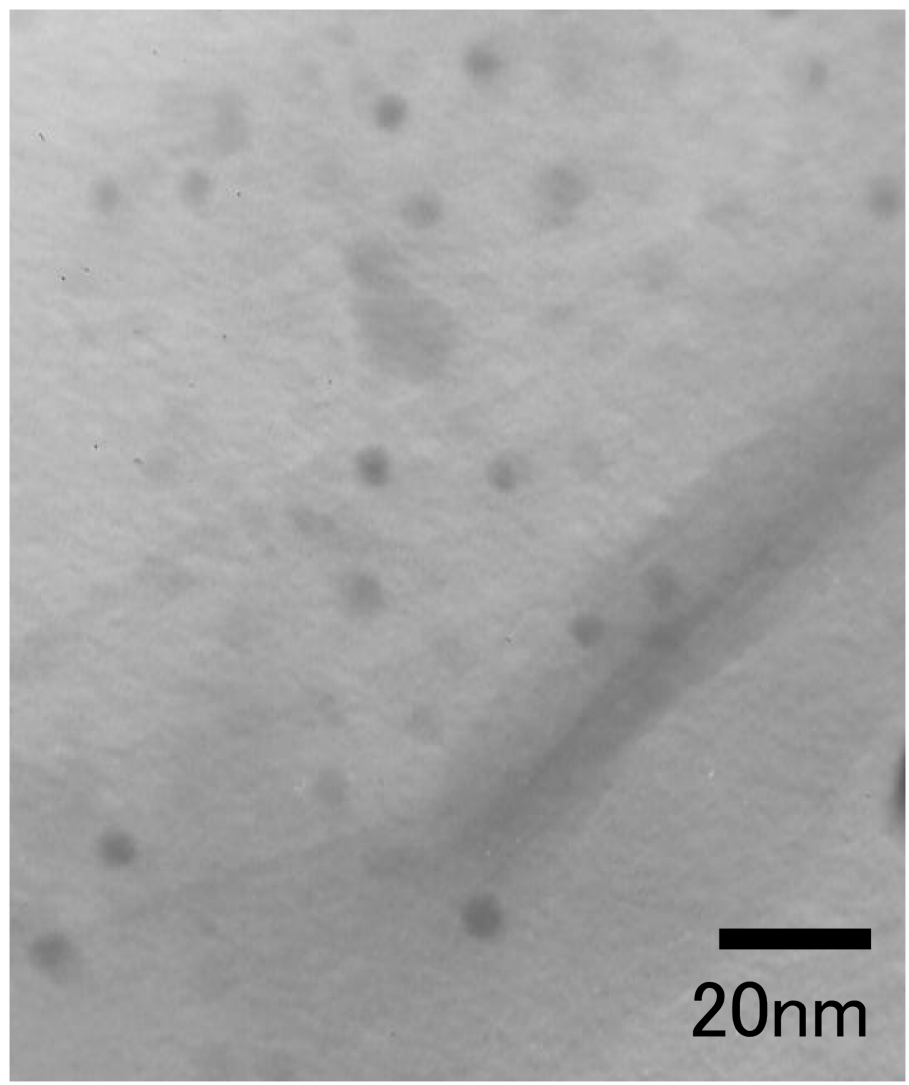

$20 \mathrm{~nm}$ 